\title{
Challenges and solutions for networking knowledge holders and better informing decision-making on biodiversity and ecosystem services
}

\author{
Carsten Nesshöver ${ }^{1} \cdot$ Barbara Livoreil $^{2,3} \cdot$ Stefan Schindler $^{4,5}$. \\ Marie Vandewalle ${ }^{1}$
}

Received: 1 February 2016/Accepted: 12 February 2016/Published online: 30 May 2016

(C) Springer Science+Business Media Dordrecht 2016

\begin{abstract}
How to effectively inform decision-making on biodiversity and ecosystem services has been under continuous debate in Europe and globally since the Convention on Biological Diversity was adopted in 1992. On the global level the Intergovernmental science-policy Platform on Biodiversity and Ecosystem Services was installed in 2012 to address this need. Yet, biodiversity and ecosystem services management have to be addressed on multiple levels, across biophysical as well as administrative scales. Also, the knowledge needed to address them has to be brought together from science, management practices and other knowledge domains to become relevant and it must be delivered in ways relevant for policies beyond the environmental sector. This Special Issue brings together papers that analyse the challenges arising from this context. Most of them are based on the EU-funded project KNEU that aimed at developing a new, integrative approach to activate knowledge holders and bring them together for targeted knowledge synthesis activities. The papers address the potential functions, structures and processes of such activities in a joint framework, the Network of Knowledge. Practical aspects are addressed via a number of trial assessments carried out in the project. All in all, they
\end{abstract}

Communicated by David Hawksworth.

This is part of the special issue on Networking Biodiversity Knowledge.

Carsten Nesshöver

carsten.nesshoever@ufz.de

1 Department of Conservation Biology \& UFZ Science-Policy Expert Group, UFZ - Helmholtz Centre for Environmental Research, Permoserstr. 15, 04318 Leipzig, Germany

2 Centre for Evidence Based Conservation, Bangor University, Bangor, Gwynedd LL57 2DG, UK

3 Present Address: Foundation for Research on Biodiversity (FRB), 195 Rue Saint Jacques, 75005 Paris, France

4 Department of Conservation Biology, Vegetation \& Landscape Ecology, University of Vienna, Rennweg 14, 1030 Vienna, Austria

5 Present Address: Environment Agency Austria, Spittelauer Lände 5, 1090 Vienna, Austria 
showcase new ways of knowledge synthesis that have the potential to complement and strengthen existing ones across scales and sectors, thus supporting an improved management of biodiversity and ecosystem services.

Keywords Science-policy-interface $\cdot$ European policy $\cdot$ Research networking · Participatory methods

\section{Introduction}

\section{Wanted: new flexible ways to make knowledge relevant to decision-making}

Policy development in the environmental sector requires credible, timely, available and relevant scientific knowledge. In particular this is the case for knowledge on biodiversity and ecosystem services in times of accelerating losses (Tittensor et al. 2014). While there are still major gaps and needs in terms of data coverage and accessibility (Wetzel et al. 2015), monitoring and indicator development (Geijzendorffer et al. 2015) and understanding of the linkages between biodiversity, ecosystem services and human well-being (Balvanera et al. 2014), major initiatives have been established at the global level. They include the Intergovernmental Platform on Biodiversity and Ecosystem Services (IPBES) as a new global science-policy interface (SPI) (Díaz et al. 2015). In the development of IPBES different needs were identified (UNEP 2010). These included knowledge assessments, policy relevant tools and methodologies, building capacity for the engagement into SPI activities and mechanisms to identify new knowledge needs (Görg et al. 2010; Larigauderie and Mooney 2010; Beck et al. 2014). A core part of IPBES is the participation of different knowledge holders from different knowledge domains, thus going beyond the contribution from the (natural) sciences alone (Tengö et al. 2014).

In the European Union there has been a long standing discussion over how to better organise the SPI on environmental issues in general and on biodiversity and ecosystem services in particular (Tinch et al. 2015). In 2006, the EU Biodiversity Strategy for 2010 called for "a support mechanism on biodiversity expertise" (European Commission 2006). Recently, such claims for improving knowledge-informed policy making have gained further momentum. For example, the Scientific Advisory Board to former European Commission President Barroso outlined current needs (Science and Technology Advisory Council to President Barroso 2013) and for the environmental sector, the 7th Environmental Action Plan (7th EAP), highlights the need to "improve the knowledge and evidence base for Union environment policy" (European Union 2013).

These claims were based on the perception that environmental policy and decisionmaking was not adequately informed by existing knowledge, or that the processes to make such knowledge available to policy- and decision-makers were unstructured or missing. An illustrative example is the discussion on the effect of neonicotinoid pesticides on bees and other pollinators. Unclear responsibilities, structures and processes about synthesising the existing knowledge led to situations where scientific knowledge was perceived to represent opposing values and interests, rather than contributing to a consolidated analysis of existing knowledge and its gaps (Walters 2013; van Lexmond et al. 2015).

At the same time, it is widely acknowledged that issues regarding biodiversity and ecosystem services are complex and often depend on a multitude of drivers, pressures and 
societal responses, requiring a broad array of knowledge from different stakeholders to understand and address them (Spierenburg 2012; Young et al. 2014).

Although a number of approaches to synthesize scientific findings on specific issues are well established (Pullin et al. 2009; Pullin and Stewart 2006; Sutherland et al. 2014; Dicks et al. 2014), the complexity of the issues related to biodiversity and ecosystem services and the different kinds of questions that need to be addressed require a better articulation and mutual understanding between knowledge producers (including scientists) and knowledge users (including policy-makers). Moreover, scientific evidence may not always be strong enough to directly derive conclusions and recommendations of high certainty. As a consequence, there is a need for complementary approaches of knowledge synthesis that are flexible enough to meet the needs of knowledge users to inform decisions in difficult policy and societal contexts (Sarkki et al. 2013; Young et al. 2014; Nesshöver et al. 2014). In this context, working at synthesizing or co-constructing knowledge by associating scientists and other actors can increase the effectiveness of the interfacing activity between science, policy and society, going further than the usual mere translation of knowledge from providers to requesters, described as the classical linear-model of policy advice (Funtowicz and Ravetz 1994; Pielke 2007).

In recent years, Europe has seen major developments improving the knowledge base on biodiversity and ecosystem services. The European Environment Agency has set up the Biodiversity Information System for Europe $\left(\mathrm{BISE}^{1}\right)$. The Joint Research Centre of the European Commission (JRC) is dedicated to strengthen its role as in-house science-service in the European Commission (Sucha et al. 2015). In addition, much scientific research and network development has been funded through the EU's Framework Programmes (Matei et al. 2011). Although time-bound projects and networks are often unable to provide effective policy support (Nesshöver et al. 2013), they represent, together with other existing networks such as learned societies, a diverse community of knowledge holders (Nesshöver et al. 2014) and constitute the starting point when trying to improve the role of scientific (and other) expertise for better informed decision-making in Europe.

To address the challenge of improving the SPI on biodiversity and ecosystem services in the European Union and to support the development of IPBES the European Platform for Biodiversity Research Strategy (EPBRS) coined the Network of Knowledge concept of "bringing together existing organisations and processes in a flexible, responsive and broadbased way $[. .$.$] helping to focus the support of science and scientists on the needs of those$ setting policy and taking decisions" through "temporary, ad hoc associations of diverse organisations to assemble and communicate knowledge adapted to the needs of clients" (EPBRS 2009). Such a network would acknowledge the existing knowledge holders (as institutions and individuals) and take its strengths from this diversity. In addition, it would heavily build on the lessons learned in the context of transdisciplinary research with respect to participation, processes and methods (Jahn et al. 2012).

This Network of Knowledge approach would explicitly address the specific situation in Europe, which has a broad and diverse landscape of knowledge holders across academia and other domains, who work and act at multiple levels, from the local, sub-national and national level, where most biodiversity relevant decisions are taken, to the European level, where major framework decisions like the Nature Directives or the Common Agriculture Policy are formulated. Such a Network of Knowledge working at multiple spatial scales, would also be flexible in terms of the scales and scope of addressed topics and could act as

\footnotetext{
${ }^{1}$ See http://biodiversity.europa.eu/.
} 
a regional complement to international bodies like IPBES that are currently lacking any sub-global structures (Beck et al. 2014).

\section{Challenges and solutions for networking knowledge}

To further develop the idea of a Network of Knowledge on biodiversity and ecosystem services, the coordination action KNEU (Developing a Knowledge Network for European expertise on biodiversity and ecosystem services to inform policy making and economic sectors, 2010-2014) was funded by the EU 7th Framework Programme on research. The project aimed at developing a blueprint for such a network based on open and transparent approaches, analysed potential challenges and trade-offs with existing interface processes and tested the new approach in trial assessments (KNEU Team 2014). This special issue is based on the project's work and brings together a number of papers that investigate functions, processes and solutions for such a Network of Knowledge. The prototype of the NoK called "BiodiversityKnowledge" was installed during the KNEU project and carried out a number of trial assessments in different areas of biodiversity and ecosystem services (Schindler et al. 2016a). The papers thus offer a concise overview of the challenges and opportunities that such flexible approaches of networking knowledge holders and requesters provide beyond the well-established approaches at the interface between science, policy and society.

As the challenges of an SPI bringing together diverse actors, are diverse in terms of functions, structures, governance, processes and outputs of such SPIs (Sarkki et al. 2013; Carmen et al. 2015), the papers of the special issue accordingly deal with different dimensions that need to be addressed in successful SPIs (Fig. 1). Nesshöver et al. (2016)

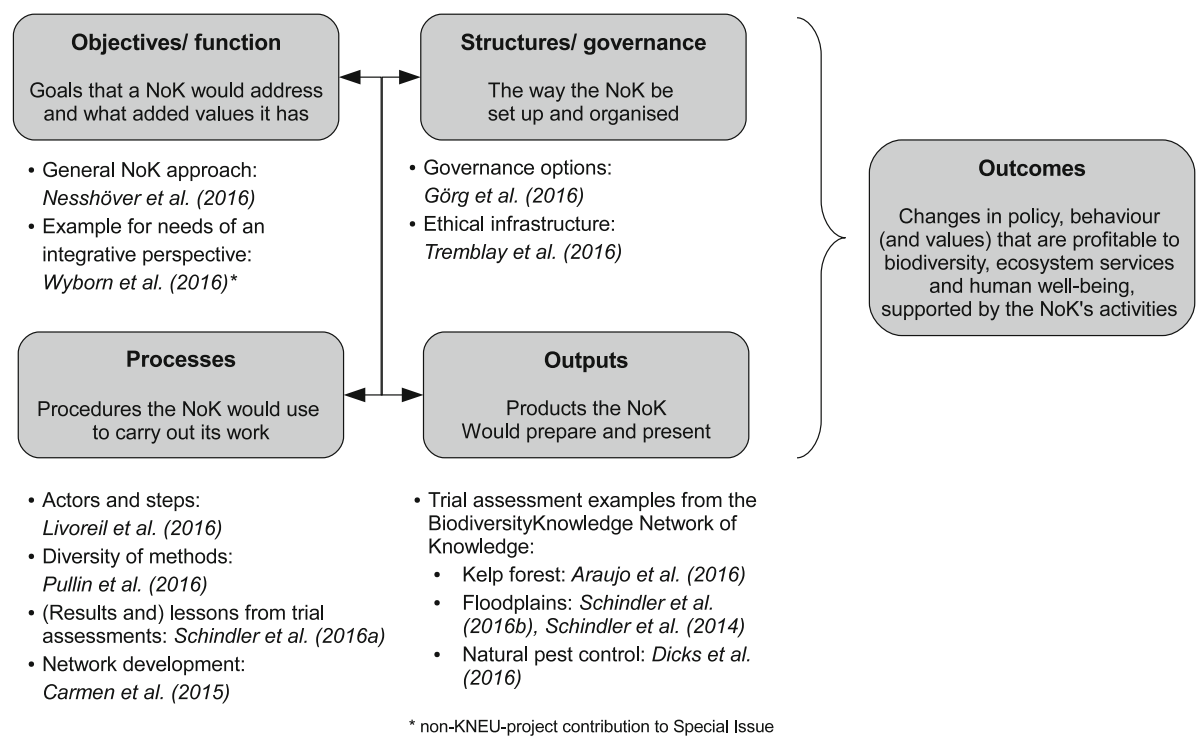

Fig. 1 Dimensions of a Network of Knowledge (NoK) approach required to become a successful sciencepolicy-society interface. Citations link to the papers in this Special Issue and few other papers that are addressing these dimensions 
present the general approach for a Network of Knowledge developed in the KNEU project and discuss in some details the current landscape of knowledge holders and interfaces on biodiversity and ecosystem services in Europe. The paper identifies the functions that a Network of Knowledge needs to address to become relevant and ensure credibility and legitimacy. These functions include building the network and ensuring capacity building on interface activities for its members, a process to discuss and identify research needs and strategies, and as major element a process to address needs from decision-making. The latter is presented in detail by Livoreil et al. (2016). The process for addressing decisionmaking needs relies on synthesizing existing knowledge (scientific, technical and expert knowledge). It highlights the necessary interaction between the requesters (from decisionmaking at the policy and/or practitioner level) and knowledge providers in order to frame the request into intelligible and explicit ways. This includes the scope and scale and the precise needs of the requester with regard to possible outcomes of the decisions (e.g., the policy maker requires knowledge to establish new regulations). It also encompasses a range of suitable methods for knowledge synthesis (see Pullin et al. 2016), with various level of confidence in the conclusions. Finally it also identifies experts to conduct the work, including the involvement of stakeholders and traditional-knowledge holders.

To achieve high legitimacy of such a process, its structures in terms of governance and ethics have to be taken into account. Görg et al. (2016) discuss the governance perspective by comparing a networking approach based on the expertise and interests of individuals and a platform approach where institutional actors play a leading role. Their paper is complemented by Tremblay et al. (2016) who address the ethical challenges of open networks by assessing the Network of Knowledge's ethical risks, which helped to develop ideas for an ethical infrastructure for such SPI.

The knowledge synthesis process developed in Livoreil et al. (2016) was tested in the KNEU project on practical examples from the areas of marine biodiversity, agricultural biodiversity and floodplain biodiversity (Fig. 1). Schindler et al. (2016a) present an overview of the results and practical lessons learned of these trial assessments. A further evaluation of the trial assessments and how a Network of Knowledge would support them is presented in Carmen et al. (2015).

To also showcase particular outcomes of these processes, Schindler et al. (2016b) present an assessment about status and biodiversity impacts of multifunctionality floodplain management in six European countries (see also Schindler et al. (2014) for a related assessment on multifunctional floodplain management and ecosystem services). Araújo et al. (2016) report on a marine assessment which addresses status, trends and drivers of kelp forest in Europe, a keystone ecosystem for biodiversity conservation and ecosystem services that is often neglected by European conservation policies. The third trial assessment addresses the effectiveness of different farm practise at enhancing natural pest regulation in agriculture, using a combination of different assessment methods (Dicks et al. 2016).

The Network of Knowledge approach and its trial assessments have one major difference to most existing environmental assessment processes: the approach offers a methodological diversity for synthesising existing knowledge for a specific question and thus allows some flexibility and reactivity to a range of questions of various scales and topics that are not addressed by global assessment processes (e.g., IPCC and IPBES) and can still be of importance at the European level. Pullin et al. (2016) present an overview of this range of methodologies spanning from systematic reviews to diverse approaches used in social sciences and transdisciplinary research. Most important, these methods are discussed in the context of the diversity of different types of requests that decision-makers 
might have to support their policies at different stages, thus offering to go beyond a onemethod-fits-all approach.

The fact that such a diverse perspective on synthesis and applying knowledge in biodiversity conservation is crucial is exemplified by the additional perspectives presented by Wyborn et al. (2016) who discuss how the understanding and application of adaption to climate change needs to be adapted in the context of biodiversity conversation and management to address different challenges with respect to scales and biodiversity governance.

To the end, all interfaces between science, policy and society in general have one generic outcome as main goal (Fig. 1): fostering changes in policy and behaviour and mutual learning for all those involved so that biodiversity and human well-being benefit from it. Novel integrative approaches of interfacing knowledge between multiple actors might seem more challenging than longer established methods of expert-focussed knowledge synthesis, but as the papers of this Special Issue of Biodiversity and Conservation show, there are a number of situations and needs from decision-making which make such new approaches worthwhile. On the EU level, this approach is now followed by the new project EKLIPSE, running until 2020 which aims at initiating a pilot phase of a Network of Knowledge on Biodiversity and Ecosystem Services. ${ }^{2}$

Acknowledgments This paper and major parts of this special issue were supported via the KNEU project, funded by the 7th Framework Programme of the European Commission (Contract No. 265299). We thank all project partners of KNEU for their valuable contributions. Also, we would like to thank the reviewers of this special issue, as well as Renuka Nidhi at the Springer's Editorial Office and David L. Hawksworth for the support and patience in the process that led to this Special Issue.

\section{References}

Araújo RM et al (2016) Status, trends and drivers of kelp forests in Europe: an expert assessment. Biodivers Conserv. doi:10.1007/s10531-016-1141-7

Balvanera P et al (2014) Linking biodiversity and ecosystem services: current uncertainties and the necessary next steps. Bioscience 64:49-57. doi:10.1093/biosci/bit003

Beck S et al (2014) Towards a reflexive turn in the governance of global environmental expertise. The cases of the IPCC and the IPBES. GAIA 23:80-87

Carmen E, Nesshöver C, Saarikoski H, Vandewalle M, Watt A, Wittmer H, Young J (2015) Creating a biodiversity science community: experiences from a European Network of Knowledge. Environ Sci Policy 54:497-504

Díaz S et al (2015) The IPBES Conceptual Framework-connecting nature and people. COSUST 14:1-16. doi:10.1016/j.cosust.2014.11.002

Dicks LV et al (2014) A transparent process for "Evidence-Informed" policy making. Conserv Lett 7:119-125. doi:10.1111/conl.12046

Dicks LV et al (2016) What works in conservation? using expert assessment of summarised evidence to identify practices that enhance natural pest control in agriculture. Biodivers Conserv. doi:10.1007/ s10531-016-1133-7

EPBRS (2009) Concept note: Network of Knowledge for biodiversity governance. European Platform for Biodiversity Research Strategy, Brussels

European Commission (2006) Communication from the Commission-halting the loss of biodiversity by 2010 - and beyond, sustaining ecosystem services for human well-being (COM (2006) 216 final). European Commission, Brussels

European Union (2013) The 7th Environment Action Programme to 2020-living well, within the limits of the planet. European Union, Brussels

Funtowicz SO, Ravetz JR (1994) Uncertainty, complexity and post-normal science. Environ Toxicol Chem 13:1881-1885

${ }^{2}$ For further information, see http://www.eklipse-mechanism.eu/ 
Geijzendorffer IR et al (2015) Bridging the gap between biodiversity data and policy reporting needs: an Essential Biodiversity Variables perspective. J Appl Ecol. doi:10.1111/1365-2664.12417

Görg C et al (2016) Governance options for Science-Policy Interfaces on biodiversity and ecosystem services: comparing a Network vs. a Platform approach. Biodivers Conserv. doi:10.1007/s10531-016$1132-8$

Görg C, Nesshöver C, Paulsch A (2010) A new link between biodiversity science and policy. GAIA 19:183-186

Jahn T, Bergmann M, Keil F (2012) Transdisciplinarity: between mainstreaming and marginalization. Ecol Econ 79:1-10. doi:10.1016/j.ecolecon.2012.04.017

KNEU Team (2014) A recommended design for "BiodiversityKnowledge", a Network of Knowledge to support decision making on biodiversity and ecosystem services in Europe. Leipzig

Larigauderie A, Mooney HA (2010) The Intergovernmental science-policy Platform on Biodiversity and Ecosystem Services: moving a step closer to an IPCC-like mechanism for biodiversity. COSUST 2:9-14

Livoreil B, Geijzendorffer IR, Pullin AS, Schindler S, Vandewalle M, Nesshöver C (2016) Biodiversity knowledge synthesis at the European scale: actors and steps. Biodivers Conserv. doi:10.1007/s10531016-1143-5

Matei S, Henckel L, Gaulthier CA, Le Roux X (2011) Biodiversity within the "Environment" theme of the 7th Framework Programme (2007-2010): funding amounts, success rates, temporal trends \& comparisons between countries. FRB, Paris

Nesshöver C et al (2013) Improving the science-policy interface of biodiversity research projects. GAIA 22:99-103

Nesshöver C et al (2014) Summary report and recommendations on Improving the Science-Policy Interface for Biodiversity and Ecosystem Services in Europe (contract: Ref No 07-0307/2013/661961/SER/B2). European Commission, Brussels

Nesshöver C et al (2016) The Network of Knowledge approach-improving the science and society dialogue on biodiversity and ecosystem services in Europe. Biodivers Conserv. doi:10.1007/s10531-0161127-5

Pielke RA (2007) The honest broker: making sense of science in policy and politics. Cambridge University Press, Cambridge

Pullin AS, Stewart GB (2006) Guidelines for systematic review in conservation and environmental management. Conserv Biol 20:1647-1656. doi:10.1111/j.1523-1739.2006.00485.x

Pullin AS, Knight TM, Watkinson AR (2009) Linking reductionist science and holistic policy using systematic reviews: unpacking environmental policy questions to construct an evidence-based framework. J Appl Ecol 46:970-975

Pullin AS et al (2016) Selecting appropriate methods of knowledge synthesis to inform biodiversity policy. Biodivers Conserv. doi:10.1007/s10531-016-1131-9

Sarkki S, Niemelä J, Tinch R, van den Hove S, Watt A, Young J (2013) Balancing credibility, relevance and legitimacy: a critical assessment of trade-offs in science-policy interfaces. Sci Public Policy 41:194-206. doi:10.1093/scipol/sct046

Schindler S et al (2014) Multifunctionality of floodplain landscapes: relating management options to ecosystem services. Landsc Ecol 29:229-244. doi:10.1007/s10980-014-9989-y

Schindler S et al (2016a) The network Biodiversity Knowledge in practice: insights from three trial assessments. Biodivers Conserv. doi:10.1007/s10531-016-1128-4

Schindler S et al (2016b) Multifunctional floodplain management and biodiversity effects: lessons from six European countries. Biodivers Conserv. doi:10.1007/s10531-016-1129-3

Science and Technology Advisory Council to President Barroso (2013) Science for an informed, sustainable and inclusive society. European Commission, Brüssel

Spierenburg M (2012) Getting the message across biodiversity science and policy interfaces-a review. GAIA 21:125-134

Sucha V, Wilkinson D, Mair D, Ahbe M, Davies S (2015) The in-house science-service in the European Commission: the evoloving role of the Joint Research Centre. In: Wilsdon J, Doubleday R (eds) Future directions for scientific advice in Europe. Centre for Science and Policy, Cambridge, pp 40-49

Sutherland WJ et al (2014) Solution scanning as a key policy tool: identifying management interventions to help maintain and enhance regulating ecosystem services. Ecol Soc. doi:10.5751/ES-06082-190203

Tengö M, Brondizio ES, Elmqvist T, Malmer P, Spierenburg M (2014) Connecting diverse knowledge systems for enhanced ecosystem governance: the multiple evidence base approach. Ambio 43:579591. doi:10.1007/s13280-014-0501-3

Tinch R, Schoumacher C, van den Hove S (2015) Exploring barriers to the integration of biodiversity concerns across EU policy. In: Gasparatos A, Willis KJ (eds) Biodiversity in the green economy. Taylor \& Francis, London, pp 309-340 
Tittensor DP et al (2014) A mid-term analysis of progress toward international biodiversity targets. Science 346:241-244

Tremblay M, Vandewalle M, Wittmer H (2016) Ethical challenges in an open system: the Network of Knowledge's ethical risks assessment and its ethical infrastructure. Biodivers Conserv. doi:10.1007/ s10531-016-1123-9

UNEP (2010) Report of the third ad hoc intergovernmental and multi-stakeholder meeting on an intergovernmental science-policy platform on biodiversity and ecosystem services ("Busan Outcome")UNEP/IPBES/3/3. UNEP, Nairobi

van Lexmond MB, Bonmatin J-M, Goulson D, Noome DA (2015) Worldwide integrated assessment on systemic pesticides. Environ Sci Pollut Res 22:1-4. doi:10.1007/s11356-014-3220-1

Walters K (2013) Data, data everywhere but we don't know what to think? Neonicotinoid insecticides and pollinators. Outlooks Pest Manag 24:151-155. doi:10.1564/v24_aug_02

Wetzel FT et al (2015) The roles and contributions of Biodiversity Observation Networks (BONs) in better tracking progress to 2020 biodiversity targets: a European case study. Biodiversity. doi:10.1080/ 14888386.2015.1075902

Wyborn C, Van Kerkhoff L, Dunlop M, Guevara O (2016) Reframing adaptation for biodiversity conservation: knowledge governance and learning at the interface between science, policy and practice. Biodivers Conserv. doi:10.1007/s10531-016-1130-x

Young JC et al (2014) Improving the science-policy dialogue to meet the challenges of biodiversity conservation: having conversations rather than talking at one-another. Biodivers Conserv 23:387-404 